\title{
Culture and organisational context: how it influences voice behaviour
}

\section{Power distance and the moderating effect of work discipline}

\author{
Eline Roomer ${ }^{1}$
}

\begin{abstract}
The purpose of this paper is to investigate how business practitioners can encourage voice behaviour (i.e. communicating opinions and concerns to improve business functioning). This paper specifically focuses on individuals' ideas of power distance as a predictor of voice. Furthermore, it evaluates the moderating effect of work discipline on this relationship between power distance and voice. Data was collected from a survey sent out to mainly Dutch and German employees who are active on the labour market. A sample of 139 responses was used to regress power distance, voice behaviour and an interaction variable of work discipline and power distance. The results show that power distance is negatively related to voice behaviour. The larger the power distance the less voice is expressed. Work discipline, the moderator, did not prove to have significant effects on the relationship. Exploratory findings show that a significant moderating effect may exist when solely looking at the private sector. This study contributes to previous research in its extension of proof of the negative relationship between power distance and voice. It furthermore contributes to the assessment of work discipline and its influence on voice behaviour.
\end{abstract}

\section{Introduction}

When seeing a problem, this should be notified to someone in charge. However, very often this is not the case. Milliken, Morrison, and Hewlin (2003) found that 85 percent of the managers and professionals they interviewed did not always report concerns they had at work. The communication of problems and opinions to superiors is referred to in the literature as employee voice behaviour (Morrison, 2014). The lack of this voice behaviour is termed employee silence (Morrison, 2014). These topics have received increasing attention from researchers in the past two decades. Research shows that silence has been the cause of organisational failures, including the implosion of Enron in 2001 (Milliken et al., 2003). Moreover, voice behaviour increases creative performance and helps companies attain a sustainable competitive advantage (Botero \& Dyne, 2009; Song, Wu, \& Gu, 2017). Additionally, the information that can be won when employees feel free in expressing their thoughts can be used for the improvement of business practices. Business practitioners should, therefore, be highly interested in understanding what helps or hinders employee voice behaviour, in order to proactively encourage employees to speak up.

Given the implications of voice behaviour, the following question arises: What can organisations do to encourage voice behaviour? One long-term strategy to pursue might be to help cultivate an organisational culture that is conducive to voice (Botero \& Dyne, 2009; Huang \& Vliert, 2004; Paddock et al., 2015; Verhezen, 2010). This paper focuses on the cultural dimension of power distance, which is an individual's perception of the inequality in power (Botero \& Dyne, 2009; Wu, 2006). Botero and Dyne (2009) suggest that a negative relationship between power distance and voice behaviour exists. This paper will further investigate this connection. In addition, it will be suggested that the organisational dimension of work discipline in the organisation will have a moderating effect on the relationship

\footnotetext{
${ }^{1}$ Eline Roomer received a bachelor degree in International Business at Maastricht University in 2017. At the moment she is interning at Accenture. Contact: elineroomer@outlook.com
} 
between power distance and voice behaviour. Work discipline refers to the amount of internal structure, regulation and control in an organisation (Hofstede, Neuijen, Ohayv, \& Sanders, 1990). When there is an easy-going work discipline this could make the connection between power distance and voice even stronger.

The special contribution this work makes to existing literature is that it investigates the moderating factor of work discipline. Botero and Dyne (2009) have suggested leader-member exchange as a moderating factor in the pathway between power distance and voice behaviour. Other research suggests a participative climate, management openness and employee involvement as moderators ( $\mathrm{Xu}$, Van De Vliert, \& Van Der Vegt, 2003, 2005). Using Hofstede's dimension of work discipline, this research will provide new insights into factors influencing voice behaviour.

In this paper, I will deal with the following question: How does power distance of an employee affect this employee's voice behaviour? Subsequently, I will investigate: In what way does the organisation's work discipline have a moderating effect on the relationship between power distance and voice behaviour?

In the remainder of this study, a theoretical background to the topics discussed will be provided. Thereafter, the methodology of the research to be conducted will be described. Results from the analysis will be provided and discussed. Furthermore, I will evaluate practical implications and provide suggestions for future research.

\section{Conceptual background}

\subsection{Voice behaviour}

In this paper, as in previous literature, the terms voice and voice behaviour will be used interchangeably. The term voice is widely used among researchers in several disciplines. It is therefore important to have a clear definition of the term which will also be used in this research. The definition of voice behaviour consists of three elements (Morrison, 2011). Firstly, voice is a verbal expression with which a sender conveys a message to a receiver within the organisation (Morrison, 2011). Secondly, the sender makes a conscious choice whether or not to convey the message. This choice is influenced by a wide variety of factors, several of which will be discussed in this research. Thirdly, the purpose of the message is to demonstrate "challenging, but constructive opinions, concerns, or ideas about workrelated issues" (Tangirala \& Ramanujam, 2008, p. 1189). Voice can, therefore, be defined as an unrestricted communication of suggestions, ideas, concerns, and opinions about issues at work with the aim to improve organisational functioning (Botero \& Dyne, 2009; Burris, Detert, \& Chiaburu, 2008; Morrison, 2011, 2014; Tangirala \& Ramanujam, 2008). This definition does not include expressive behaviours such as notifying external agencies about misconduct in an organisation (i.e. whistleblowing) or making anonymous suggestions, as these examples are not openly communicated or received by someone in the organisation (Maynes \& Podsakoff, 2014).

As can be concluded from the definition, voice includes a wide range of communication. The definition is not limited to verbal communication, it may also include actions such as sending emails or writing a memo (Withey \& Cooper, 1989). Moreover, voice can be directed towards superiors or members of a team; it can be upward or lateral communication (Robbins \& Judge, 2016). Additionally, it can be ideas or suggestions on how to do things within the firm differently, or it can address serious problems. In this, one can make the distinction between prohibitive and promotive voice. Prohibitive voice describes "expressions of concerns about work practices, incidents, or employee behaviour that are harmful for the organisation" (Liang, Farh, \& Farh, 2012, p. 75). Prohibitive voice challenges the

$$
2 \mid \begin{array}{l|l}
\text { Marble } \\
\text { Research } \\
\text { Papers }
\end{array}
$$


status quo and prevents harm. Although the term has a negative connotation, the results can also be very positive. Promotive behaviour is an expression of ideas and suggestions on improving the functioning of the organisation (Liang et al., 2012). This type of voice promotes change and focusses on an ideal goal for the company to reach.

There are wide ranging determinants for employee voice. One can group the variables that motivate voice into individual disposition, job and organisational attitudes and perceptions, emotions and beliefs, supervisor and leader behaviour, and other contextual factors (Morrison, 2011). The focus of this research will focus on the variables power distance (organisational perception) and work discipline (organisational attitudes and perceptions).

\subsection{Power distance}

Hofstede (1984, p. 21) defined culture as "the collective programming of the mind which distinguishes the members of one human group from another". A meaningful way of studying differences in national cultures is on the basis of Hofstede's six dimensions. Hofstede, Hofstede, and Minkov (2010) found that countries could be compared on the basis of power distance, individualism, masculinity, uncertainty avoidance, long-term orientation and indulgence. The focus on power distance in this research is based on its connections to voice and silence made in previous studies (Botero \& Dyne, 2009; Wu, 2006). Power distance describes how people deal with inequality (Hofstede et al., 2010). Power distance is defined as the degree to which the less powerful members of a society expect and accept that power is distributed unequally (Hofstede et al., 2010).

Hofstede (1984) originally described power distance at the societal level. Recent research has, however, focussed on individual variability in power distance values, instead of the national variability (Botero \& Dyne, 2009; Wu 2006). This is because assessment on country-level is a form of stereotyping which ignores within-country variance (Taras, Kirkman, \& Steel, 2010). These within-country variabilities were also confirmed by Hofstede et al. (2010). They found variability in different social classes, education levels and occupation. Thus, in order to account for these personal differences, this research too looks at the definition of power distance on the individual level. Whenever power distance is mentioned in the remainder of this paper, this is the individual variance in power distance.

Hofstede et al. (2010) characterise power distance as a score that informs about dependence. When the feeling of power distance is large there is a considerably larger dependency of subordinates on their executive. People with a large power distance accept the hierarchy in organisations. When the degree of power distance is low people want to change the distribution of power to decrease inequality. (Hofstede et al., 2010). In a situation of large power distance employees are less likely to engage in extra-role behaviours, as they are more bound to their prescribed tasks (Costigan et al., 2006). On the other hand, individuals in a small power distance culture are more likely to believe that they have a say in organisational decision-making (Landau, 2009).

Because of these above-described outcomes of power distance, as well as the fact that power distance should influence the perception of how supervisors and subordinates interact with each other, it is reasonable to assume a negative relation between power distance and voice behaviour (Botero \& Dyne, 2009). Consequently, when power distance is large, the individual will be less likely to speak up. MacNab and Worthley (2008) already found a negative relation between large power distance and internal reporting for samples in Northern America. Additionally, Xu, van de Vliert, and van der Vegt (2005) found a negative relationship between power distance and voice in their study of a large multinational corporation. Accordingly, I propose that:

Hypothesis 1: An individual's power distance will be negatively related to voice behaviour.

$$
\begin{array}{r}
\text { Culture and organisational } \\
\text { context: how it } \\
\text { influences voice behaviour }
\end{array}
$$




\subsection{Work discipline}

Besides national culture, Hofstede, Neuijen, Ohayv, and Sanders (1990) also studied organisational culture. Organisational culture, in general, has several characteristics; it is holistic, historically determined, related to anthropological concepts, socially constructed, soft, and difficult to change (Hofstede et al., 1990). Based on in-depth interviews of twenty business units in several organisations the researchers constructed six dimensions on which organisational cultures differ; Process-Oriented vs. Results-Oriented, Employee-Oriented vs. Job-Oriented, Parochial vs. Professional, Open System vs. Closed System, Loose Control vs. Tight Control, and Normative vs. Pragmatic. This paper specifically focuses on control, which is also described as either an easy-going work discipline or a strict work discipline.

The dimension of work discipline refers to the amount of control, internal structuring and discipline given in an organisation (Hofstede et al., 1990). On the one hand, if the work discipline is easy-going there is a loose internal structure, little control, and processes are more flexible and less predictable. On the other hand, given strict work discipline, people are meticulous, punctual, and follow a clear set of rules. These people mentioned that meeting times were kept very punctually, employees are very cost conscious, and it is very rare to make jokes about the company or job (Hofstede et al., 2010).

The perception of work discipline is influenced by several factors in the organisation. Hofstede et al. (2010) found various significant relationships between organisational situations and the perception of control. First of all, when the number of employees recently increased, control was felt as looser, and departments that had recently experienced layoffs felt a stricter work discipline. Also, when a department works with risky products or needs to deliver precision in services, there is a larger feeling of tight organisational control. The existence of strict rules on dress code and dignified behaviour results in a tighter assessment of control. When no such rules exist, control is experienced to be looser. Moreover, as a consequence, absenteeism is found to be lower when there is an easy-going work discipline (Hofstede et al., 2010). Additionally, flexibility in control and planning leads to improved business performance (Dibrell, Craig, \& Neubaum, 2014). Besides, making occasional jokes about your work will have a positive effect on work performance and satisfaction (Mesmer-Magnus, Glew, \& Viswesvaran, 2012). In a situation of more satisfaction, employees will be more willing to contribute to the company's success and speak up about problems.

To my knowledge, no previous research has been done on the relationship between work discipline and voice behaviour. Nor are there any previous studies on work disciplines' moderating effect. However, following Hofstede's line of reasoning in the consequences of loose and tight control, including the positive effects on absenteeism, performance and satisfaction, it is expected that if there is an easygoing work discipline, the previously described relationship between power distance and voice will be reinforced. If, however, there is a strong work discipline, it may weaken the negative effect of power distance on voice behaviour. I therefore propose:

Hypothesis 2: Work discipline will have a moderating effect on the relationship between power distance and voice behaviour (Figure 1). 


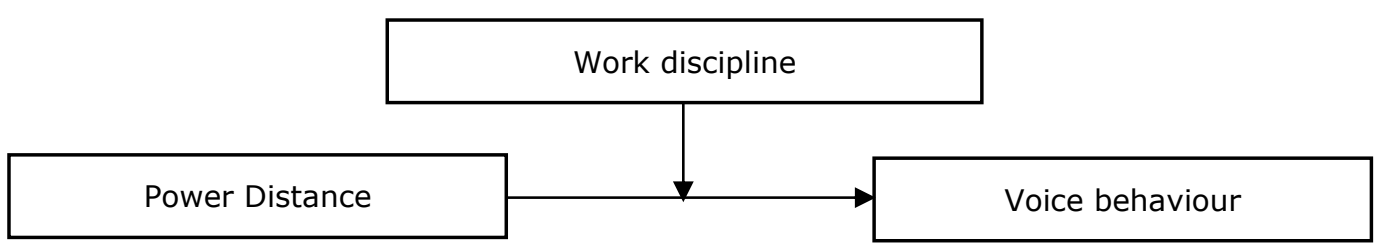

Figure $1 . \quad$ Moderator model

\section{Methods}

\subsection{Data and sample}

For this study, three bachelor thesis students worked together in collecting data. A total of 191 questionnaires were collected to investigate voice behaviour and various factors influencing the degree of voice behaviour employees are involved in. Participation among respondents was voluntary and anonymity was guaranteed.

List-wise deletion of respondents with one or more missing variables on the study variables $(N$ $=52$ ) resulted in a final sample of 139 respondents. The target of 107 respondents, based on the rule by Field (2009) to use 104 responses plus the number of predictors, was here with reached.

Responses were gathered via two sampling methods, convenience and snowball sampling. First, web links to the questionnaire were shared through email and professional media like LinkedIn. Second, to increase the sample size, data was collected using snowball sampling. Snowball sampling is an effective manner to receive data in situations where members are harder to reach, for instance when surveys concern sensitive questions (Valerio et al., 2016). As voice behaviour is classified as a sensitive topic, these sampling methods were regarded as most appropriate (Hirschman, 1970). Accordingly, we were able to gather data from a wide range of people from different organisations, mainly in the Netherlands and Germany. Organisations targeted include, amongst others, a car manufacturer, a hotel, and a hospital.

At the time of data collection, the average age of the respondents was $39.32(S D=14.55)$. Of the respondents 60 percent were female. The average tenure of the sample was nine years and five months. Sixty-four percent of the respondents were Dutch, 30 percent was German and the last 5 percent had another nationality. Most of the respondents worked in the healthcare sector (37.14\%). Other sectors largely represented were industrial $(13.57 \%)$, utilities (10\%), customer staples $(9.29 \%)$, customer discretionary (9.29\%), financial (7.86\%) and information technology (7.86\%).

\subsection{Measures}

Respondents had the option to answer all questions in English, Dutch or German. Careful translations were made on the basis of accepted variables that are widely used in previous studies (Botero \& Dyne, 2009; Guenter, Schreurs, van Emmerik, \& Sun, 2017; Kuchinke \& Cornachione, 2010; Mowbray, Wilkinson, \& Tse, 2015; Yuan \& Zhou, 2015).

Voice behaviour. To obtain information about voice behaviour, the dependent variable in this study, a four-item measure suggested by Liu, Tangirala, and Ramanujam (2013) was used. This measure includes the following items: how often an employee makes recommendation concerning issues; how often an employee encourages a supervisor to get involved in issues; how often an employee communicates his/her opinion about work issues even if they are against the standard, and

$$
\begin{array}{r}
\text { Culture and organisational } \\
\text { context: how it } \\
\text { influences voice behaviour }
\end{array}
$$


how often an employee speaks up about ideas for new projects or changes in procedures. When studying voice behaviour, self-reporting is preferred over other report because workers themselves know best when they deliberately report or withhold input (Tangirala \& Ramanujam, 2008). A sevenpoint Likert scale (1, strongly disagree, 7, strongly agree) was provided to measure the items. Cronbach's alpha was 0.904 . The mean of the four items was used to compose the variable "voice behaviour".

Power distance. Power distance was assessed using a five-item measure developed by Wu (2006). This measure of power distance is widely used to measure individual variance of the cultural perception (Botero \& Dyne, 2009; Yuan \& Zhou, 2015). Sample items read "It is frequently necessary for a manager to use authority and power when dealing with subordinates" and "Employees should not disagree with management decisions" (1, strongly disagree, 5, strongly agree). Cronbach's alpha was 0.590. The mean of the five variables was used to compose the variable "power distance" (PD).

Work discipline. Work discipline was assessed by dimensions that were used in the initial research about the six dimensions of organisational culture. Hofstede et al. (1990) used measures about the tightness of formal control systems, associated with strict unwritten codes about dignified behaviour and dress codes. For control he used a four-item scale including "Everybody is cost-conscious" and "Always speak seriously of organisation and job" (1, strongly disagree, 5, strongly agree). The four items initially had a Cronbach's alpha was too low. Therefore, the scale "Typical is member wellgroomed" was taken out of the analysis (Cronbach's alpha: 0.547). The mean of the three remaining items was used to compose the variable of "work discipline" (WD).

Control variables. In all analyses, gender, age, tenure, nationality, and industry were controlled for, because of their potential link with the outcome variables in the study. Gender was included because research showed that males are more likely to speak up than females (LePine \& van Dyne, 1998). Additionally, older employees are more likely to express their opinions than younger employees (Luchak, 2003). Tenure was controlled for, as people who work longer with an employer can be more comfortable expressing concerns (Stamper \& van Dyne, 2001). As power distance was originally analysed at societal level, and Hofstede et al. (1990) differentiated levels of power distance to be different for different countries (Netherlands $=38$, Germany $=35$, Belgium, 65) this was a reason to include nationality as a control variable. An industry variable was added, because of the potential difference between public and private institutions (healthcare as an example of a public sector). The diverse types of organisations portray differences in the importance of creativity and innovation, and with that voice (Baron \& Tang, 2011).

\section{Results}

\subsection{Data analysis}

All analyses were conducted using SPSS (Version 24) (IBM Corp., 2016). Prior to hypothesis testing, descriptive statistics were compared to check for any odds. Bivariate correlations were computed to evaluate the preliminary findings. Thereafter, the work discipline and power distance variables were centred around their sample means (i.e. group-mean centring) to reduce the possible problems with multicollinearity and to get an undistorted estimate of the moderating influence that both culture variables have on the outcome (Brincks et al., 2016).

\footnotetext{
$6 \mid \begin{aligned} & \text { Marble } \\ & \text { Research } \\ & \text { Papers }\end{aligned}$
} 
In the first model, the direct relationship between power distance and voice behaviour was tested with a multiple regression. In the second model, the cross-level term PD*WD was added to examine the crosslevel interaction hypothesis; that work discipline would moderate the effect of the first model.

\subsection{Preliminary analysis}

Means, standard deviations, and correlations of the study variables are represented in Table 1. Bivariate correlation results show a negative relationship between power distance and voice. Interestingly, age and tenure show a positive correlation with voice behaviour and power distance beliefs $(p<.01)$. It is furthermore interesting to note that power distance, which in its initial idea is a societal measure, is not significantly correlated with nationality.

Table 1: Means, standard deviations, and correlations ${ }^{a}$

\begin{tabular}{|c|c|c|c|c|c|c|c|c|c|}
\hline Variable & Mean & $S D$ & 1 & 2 & 3 & 4 & 5 & 6 & 7 \\
\hline 1. Voice behaviour & 5.21 & 1.17 & .90 & & & & & & \\
\hline 2. Power distance & 2.01 & .61 & $-.27 * *$ & .59 & & & & & \\
\hline 3. Work discipline & 2.77 & .79 & -.43 & -.14 & .55 & & & & \\
\hline 4. Age & 39.32 & 14.55 & $.39 * *$ & $-.22 * *$ & -.15 & & & & \\
\hline 5. Tenure & 9.44 & 9.36 & $.32 * *$ & $-.26 * *$ & .01 & $.74 * *$ & & & \\
\hline 6. Nationality & 2.53 & 1.07 & -.49 & .16 & $-.25 * *$ & $-.17 *$ & $-.25 * *$ & & \\
\hline 7. Gender & 1.60 & .49 & $-.23 * *$ & -.04 & -.12 & $-.27 * *$ & $-.21 * *$ & -.04 & \\
\hline 8. Industry & 5.96 & 2.08 & .09 & -.07 & .08 & -.13 & -.11 & -.00 & .10 \\
\hline
\end{tabular}

Note: $n^{a}=139$ individuals. Cronbach's alphas are reported in boldface along the diagonal.

$* p<.05, * * p<.01$

\subsection{Hypothesis testing}

The results of the linear regression analysis with voice behaviour, power distance, and work discipline are presented in Table 2. Model 1 was first tested, to examine the direct influence of power distance on voice behaviour. The linear regression performed showed that power distance was negatively and significantly associated with voice behaviour $(\gamma=-.40, p<.05)$. Hypothesis 1 was thus supported.

Table 2: Estimates for models predicting voice behaviour

\begin{tabular}{lll}
\hline Variable & Model 1 & Model 2 \\
\hline Intercept & 4.48 & 4.37 \\
Power distance & $-.40 *$ & $-.39 *$ \\
Work discipline & -.08 & -.10 \\
Power distance * Work discipline & & .22 \\
Age & $.02 *$ & $.02 *$ \\
Tenure & .01 & .01 \\
Nationality & .03 & .03 \\
Gender & -.40 & $-.39 *$ \\
Industry & .08 & .08 \\
\hline
\end{tabular}

Note: $n^{a}=139$ individuals.

$* p<.05, * * p<.01$ 
Hypothesis 2 predicted that work discipline would moderate the relationship between power distance and voice behaviour. When testing this moderation hypothesis (Model 2), there was no significant relationship found between the interaction variable and voice $(\gamma=.22$, ns). Hence, there was no support found for hypothesis 2 .

\subsection{Exploratory findings}

More than 100 published comparisons between public and private organisations provide proof for the differences between the two (Rainey, 2015). Public institutions tend to have other organisational cultures, and its employees have different work motives and attitudes towards their jobs (Bullock, Stritch, \& Rainey, 2015). Employees in public organisations are thought to have a unique set of values, attract a particular type of employees, and are motivated by different condition (Vandenabeele, 2007). Because of the diversity in behaviour of employees in public and private institutions, an industry-specific analysis was conducted (Goulet \& Frank, 2002; B. E. Wright, 2001).

When the respondents from the healthcare sector (public sector industry) were excluded from the data, the negative relationship between power distance and voice behaviour was again confirmed $(\gamma$ $=-.57, p<.01)$. Additionally, the moderation effect from work discipline was found to be significant when employees from the healthcare sector are removed from the sample $(\gamma=.53, p<.05)$.

Figure 2 suggests the negative association of power distance and voice behaviour decreases when work discipline is higher. Thus, in the case of a model without the healthcare sector, this finding would be in line with what was expected in hypothesis 2. Figure 2 also suggests that, no matter the degree of work discipline, employees are less likely to speak up when power distance is large.

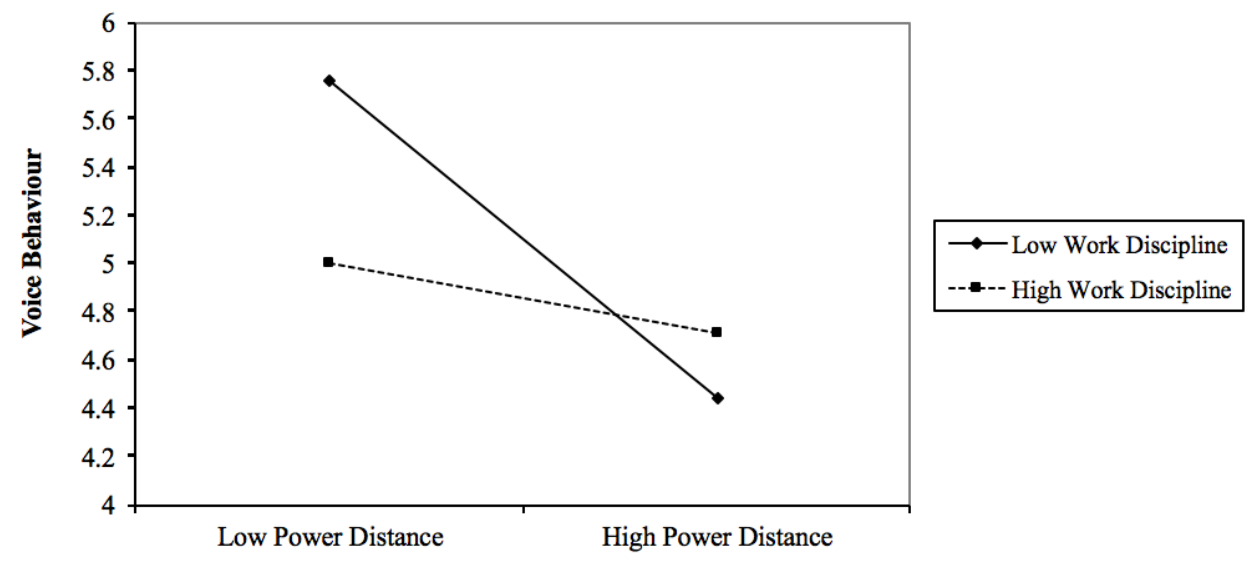

Figure 2. Interactive effect between power distance and work discipline on voice behaviour, adapted from Dawson (2014)

\section{Discussion}

In this study, a model was tested studying the association between power distance and voice behaviour and how work discipline moderated this relationship. Studies with samples from large multinational organisations and samples from North America showed the negative relationship between power distance and voice (MacNab \& Worthley, 2008). Results from this study, obtained from 139 observations in a wide variety of industries, also give support to the hypothesised negative relation between power distance and voice behaviour. Employees who experience a high degree of power distance spoke up less than their counterparts who experienced smaller power distance. The second hypothesis, concerning the

\footnotetext{
8 \begin{tabular}{l|l} 
Marble \\
Research \\
Papers
\end{tabular}
} 
moderating effect of work discipline, was not found to be significant. In situations of small power distance, employees were more likely to express opinions no matter the level of control.

\subsection{Theoretical implications}

Concerning the relationship between power distance and voice behaviour, the expected results were found. Therefore, this study provides further prove for the negative relationship between power distance and voice. This negative relationship implies that indeed a larger (smaller) power distance results in less (more) voice behaviour. Results found in previous research have hereby been reconfirmed (MacNab \& Worthley, 2008). However, whereas previous research primarily focussed on American employees and multinational corporations (Landau, 2009), this study used mainly European (Dutch and German) data and respondents from small, large, public and private organisations, thereby extending the evidence for the negative connection between power distance and voice.

The second contribution involves the assessment of work discipline and its influence on voice behaviour. Although work discipline, at least as characterised by Hofstede et al. (1990), did not moderate the link between power distance and voice, the idea of its relationship offers opportunities for future research. The lack of evidence in this case may be caused by the specific characteristics of this sample. The large percentage of our sample working in the healthcare sector may be an explanation, as public workers are known to be different in their behaviour from people working in private sectors (Goulet \& Frank, 2002; Wright, 2001). Employees in the public sector are more motivated by their contribution to the public service and society (Wright, Donald, \& Sanjay, 2012). Moreover, public workers place less emphasis on their income (Crewson, 1997) and show less organisational commitment (Bullock et al., 2015). Specifically, the idea that public workers are less committed to their organisation may contribute to the absence of evidence in this case. Additionally, the items explaining work discipline did not show a high level of internal consistency (Cronbach's alpha $=0.50$ ).

Interestingly, a significant moderating relationship was found when the healthcare sector was excluded from the sample. This suggests that there are different impacts from control in public and private institutions. In private corporations, this would imply that a lower (higher) level of control could increase (decrease) the effect of power distance on voice behaviour. In a situation of little power distance, workers express their opinion significantly more often when the level of control is low as well. When the level of power distance is large, low control has a damaging effect on voice behaviour. To confirm these expectations, more research addressing the moderating role of voice behaviour in the private sector specifically is needed.

\subsection{Potential limitations and suggestions for future research}

This study has some potential limitations. First, it should be recognised that the data used came from a cross-sectional survey. Causality can therefore not be definitely implied. Although the results are in line with those from previous studies, future research should use longitudinal designs to study the effects of power distance on voice behaviour in a broad context, as well as the moderating role of work discipline. When time-series data is used the mediating role of work discipline can be evaluated as well.

Second, in the survey asked respondents to respond in a self-reported manner. This was done because, unlike observable behaviour, the intentional withholding of information is most clearly known by the person who is withholding information (Tangirala \& Ramanujam, 2008). However, self-reporting comes with the risk that people tell "more than they can know" in this approach (Nisbett \& Wilson, 1977). Although the design of the questions followed the procedures in previous research on the topic (Botero \& Dyne, 2009; Guenter et al., 2017; Mowbray et al., 2015; Yuan \& Zhou, 2015), consecutive studies may

$$
\begin{array}{r}
\text { Culture and organisational } \\
\text { context: how it } \\
\text { influences voice behaviour }
\end{array}
$$


want to use a combination of self-report and observable behaviour to further decrease the likelihood of common method bias (Nisbett \& Wilson, 1977).

A third limitation is that Cronbach's alpha for the power distance variable, as well as the variable for work discipline was considerably low. Acceptable internal consistency has Cronbach's alphas ranging from .70 and .90 (Bland \& Altman, 1997; DeVellis, 2012; Walumbwa, Avolio, Gardner, Wernsing, \& Peterson, 2008); the alpha's in this study were .59 and .50 (after removal of one of the items) respectively. These low values of the alpha can be explained by a low number of questions, heterogeneous constructs, or poor interrelatedness between the items (Tavakol \& Dennick, 2011). It should be noted that the measures that were used for the variables were consistent with previous research, where the Cronbach's alphas were acceptable. When a larger sample is used, this problem should not occur.

For future research it will furthermore be value adding to look at specific industries. As this study found reason to believe there is a difference in the role of power distance, and the moderating role of work discipline in public and private institutions, for future studies it is useful to further investigate this relationship. Moreover, it would be interesting for forthcoming studies to investigate other moderating roles in the relationship between power distance and voice behaviour. For instance, the effect of proactive personality, transformational leadership and group voice climate can be evaluated (Hsiung \& Tsai, 2017; Jun, Xiaoping, Juncheng, \& Jiaxin, 2014).

\subsection{Practical implications}

This study found support for the negative effects of power distance on voice behaviour. As voice behaviour is of convincing importance for organisational learning and innovation (Landau, 2009) it is interesting for business practitioners to carefully assess how to manage the power distance orientation of their employees. An individual's perception of power distance is hard to change, and in most cases adapting to, rather than changing this perception, is advisable. However, for managers or supervisors it is beneficial to give employees autonomy, encourage openness and treat them with respect. This affects trusts, and indirectly also decreases the feeling of power distance. (Rao \& Pearce, 2016).

As hypothesis two was only supported when excluding the healthcare sector, and this difference in public and private organisations was not initially hypothesised, there is a need for caution in thinking about implications for managers. If, however, the results were replicated in other samples and more defined studies, this would indicate that adapting the level of control to the cultural dimension of power distance could improve the communication between managers and employees. A simple slope analysis found that in a situation of low work discipline there is indeed a negative relationship between power distance and voice. If, however, work discipline is high, this negative relationship diminishes. This implies that higher levels of control, a formal environment and stricter rules may help to reduce the negative effects from power distance on voice. In other words, employees will be more likely to express their opinions in situations where power distance and work discipline are high, as opposed to a situation where power distance is large and work discipline is low. In addition, we saw that power distance was not significantly correlated with nationality. Thus, managers should not assume that all employees have cultural values. Behaviour should be adjusted according to individual's needs.

\footnotetext{
$10 \mid$\begin{tabular}{l|l} 
Marble \\
Research \\
Papers
\end{tabular}
} 


\section{Conclusion}

This study added to previous studies in its extension to proof the relationship between power distance and voice behaviour. The negative relation between these two variables was reconfirmed in this research. Additionally, this report contributed in the exploration of the moderating role of work discipline in the relationship between power distance and voice behaviour. In the overall sample, no significant findings were found for this interaction effect. There is reason to suggest a significant moderating impact in private organisations; however, further research is needed to explore work discipline's moderating impact and its differences in the public and private organisations.

\section{References}

Baron, R. A., \& Tang, J. (2011). The role of entrepreneurs in firm-level innovation: Joint effects of positive affect, creativity, and environmental dynamism. Journal of Business Venturing, 26(1), 49-60. doi:http://dx.doi.org/10.1016/j.jbusvent.2009.06.002

Bland, J. M., \& Altman, D. G. (1997). Statistics Notes: Cronbach's Alpha. BMJ: British Medical Journal, 314(7080), 572-572.

Botero, I. C., \& Dyne, L. v. (2009). Employee Voice Behavior: Interactive Effects of LMX and Power Distance in the United States and Colombia. Management Communication Quarterly, 23(1), 84104. doi: $10.1177 / 0893318909335415$

Brincks, A. M., Enders, C. K., Llabre, M. M., Bulotsky-Shearer, R. J., Prado, G., \& Feaster, D. J. (2016). Centering Predictor Variables in Three-Level Contextual Models. Multivariate behavioral research, 52(2): 149-163.

Bullock, J. B., Stritch, J. M., \& Rainey, H. G. (2015). International Comparison of Public and Private Employees' Work Motives, Attitutes, and Perceived Rewards. Public Administration Review, 75(3), 479-489. doi:DOI: 10.1111/puar.12356

Burris, E. R., Detert, J. R., \& Chiaburu, D. S. (2008). Quitting before leaving: the mediating effects of psychological attachment and detachment on voice. The Journal of applied psychology, 93(4), 912-922.

Costigan, R. D., Insinga, R. C., Berman, J. J., Itler, S. S., Kranas, G., \& Kureshov, V. (2006). The effect of employee trust of the supervisor on enterprising behavior: A cross-cultural comparison. Journal of Business and Psychology, 21(2), 273-291.

Crewson, P. E. (1997). Public-Service Motivation: Building Empirical Evidence of Incidence and Effect. Journal of Public Administration Research and Theory, 7(4), 499-511.

Dawson, J. F. (2014). Moderation in management research: Whay, why, when and how. Journal of Business and Psychology, 29, 1-19.

DeVellis, R. F. (2012). Scale development : theory and applications (3rd ed. ed.). Thousand Oaks, Calif. :: SAGE.

Dibrell, C., Craig, J. B., \& Neubaum, D. O. (2014). Linking the formal strategic planning process, planning flexibility, and innovativeness to firm performance. Journal of Business Research, 67(9), 2000-2007. doi:http://dx.doi.org/10.1016/j.jbusres.2013.10.011

Field, A. (2009). Discovering statistics using SPSS (3rd ed. ed.). Los Angeles, Calif.: Sage.

Goulet, L. R., \& Frank, M. L. (2002). Organizational Commitment across Three Sectors: Public, Nonprofit, and For-profit. Public Personnel Management, 31(2), 201-210. doi:doi: $10.1177 / 009102600203100206$ 
Guenter, H., Schreurs, B., van Emmerik, I. J. H., \& Sun, S. (2017). What Does it Take to Break the Silence in Teams: Authentic Leadership and/or Proactive Followership? Applied Psychology, 66(1), 49-77. doi:10.1111/apps.12076

Hirschman, A. O. (1970). Exit, voice, and loyalty : responses to decline in firms, organizations, and states. Cambridge, Mass. :: Harvard University Press.

Hofstede, G. (1984). Culture's consequences : international differences in work-related values (2nd abridged ed. ed.). Beverly Hills, CA :: Sage Publications.

Hofstede, G., Hofstede, G. J., \& Minkov, M. (2010). Cultures and organizations: software of the mind (3 ed.). Maidenhead: McGraw-Hill.

Hofstede, G., Neuijen, B., Ohayv, D. D., \& Sanders, G. (1990). Measuring Organizational Cultures: A Qualitative and Quantitative Study Across Twenty Cases. Administrative Science Quarterly, 35(2), 286-316. doi:10.2307/2393392

Hsiung, H. H., \& Tsai, W. C. (2017). The Joint Moderating Effects of Activated Negative Moods and Group Voice Climate on the Relationship between Power Distance Orientation and Employee Voice Behavior. Applied Psychology.

IBM Corp. Released 2016. IBM SPSS Statistics for Macintosh, Version 24.0. Armonk, NY: IBM Corp.

Jun, X. I. E., Xiaoping, C. H. U., Juncheng, Z., \& Jiaxin, H. (2014). Proactive personality and voice behavior: the influence of voice self-efficacy and delegation. Social Behavior \& Personality, 42(7), 1191-1200. doi:10.2224/sbp.2014.42.7.1191

Kuchinke, K. P., \& Cornachione, E. B. (2010). The meaning of work and performance-focused work attitudes among midlevel managers in the United States and Brazil. Performance Improvement Quarterly, 23(3), 57-76. doi:10.1002/piq.20090

Landau, J. (2009). To speak or not to speak: predictors of voice propensity. Journal of Organizational Culture, Communications \& Conflict, 13(1), 35-54.

LePine, J. A., \& van Dyne, L. (1998). Predicting voice behavior in work groups. Journal of Applied Psychology, 83(6), 853-868. doi:10.1037/0021-9010.83.6.853

Liang, J., Farh, C., \& Farh, L. (2012). A two-wave examination of the psychological antecedents of voice behavior. Academy of Management Journal, 55, 71-92. doi:10.5465/amj.2010.0176

Luchak, A. A. (2003). What Kind of Voice Do Loyal Employees Use? British Journal of Industrial Relations, 41(1), 115-134. doi:10.1111/1467-8543.00264

MacNab, B. R., \& Worthley, R. (2008). Self-efficacy as an intrapersonal predictor for internal whistleblowing: A US and Canada examination. Journal of Business Ethics, 79(4), 407-421.

Maynes, T. D., \& Podsakoff, P. M. (2014). Speaking More Broadly: An Examination of the Nature, Antecedents, and Consequences of an Expanded Set of Employee Voice Behaviors. Journal of Applied Psychology, 99(1), 87-112. doi:10.1037/a0034284

Mesmer-Magnus, J., Glew, D. J., \& Viswesvaran, C. (2012). A meta-analysis of positive humor in the workplace. Journal of Managerial Psychology, 27(2), 155-190. doi:doi:10.1108/02683941211199554

Morrison, E. W. (2011). Employee Voice Behavior: Integration and Directions for Future Research. The Academy of Management Annals, 5(1), 373-412. doi:10.1080/19416520.2011.574506

Morrison, E. W. (2014). Employee Voice and Silence. The Annual Review of Organizational Psychology and Organizational Behavior, 1, 173-197.

Mowbray, P. K., Wilkinson, A., \& Tse, H. H. M. (2015). An Integrative Review of Employee Voice: Identifying a Common Conceptualization and Research Agenda. International Journal of Management Reviews, 17(3), 382-400. doi:10.1111/ijmr.12045

12 Research

Papers 
Nisbett, R. E., \& Wilson, T. D. (1977). Telling more than we can know: Verbal reports on mental processes. Psychological Review, 84, 231-259.

Rainey, H. G. (2015). Understanding and managing public organisations (5th ed.). San Francisco: Jossey-Bass.

Rao, A. N., \& Pearce, J. L. (2016). Should management practice adapt to cultural values? The evidence against power distance adaptation. Cross Cultural \& Strategic Management, 23(2), 257-286. doi:doi: 10.1108/CCSM-03-2014-0035

Robbins, S. P., \& Judge, T. A. (2016). Chapter 11: Communication Organizational Behavior (17 ed., pp. 380-417). Harlow: Pearson Education Limited.

Stamper, C. L., \& van Dyne, L. (2001). Work status and organizational citizenship behavior: a field study of restaurant employees. Journal of Organizational Behavior, 22(5), 517-536. doi: $10.1002 /$ job. 100

Tangirala, S., \& Ramanujam, R. (2008). Exploring nonlinearity in employee voice: the effects of personal control and organizational identification. Academy of Management Journal, 51(6), 1189-1203.

Tavakol, M., \& Dennick, R. (2011). Making sense of Cronbach's alpha. International Journal of Medical Education, 2, 53-55. doi:10.5116/ijme.4dfb.8dfd

Valerio, M. A., Rodriguez, N., Winkler, P., Lopez, J., Dennison, M., Liang, Y., \& Turner, B. J. (2016). Comparing two sampling methods to engage hard-to-reach communities in research priority setting. BMC Medical Research Methodology, 16(1), 146. doi:10.1186/s12874-016-0242-z

Vandenabeele, W. (2007). Toward a public administration theory of public service motivation. Public Management Review, 9(4), 545-556. doi:10.1080/14719030701726697

Walumbwa, F. O., Avolio, B. J., Gardner, W. L., Wernsing, T. S., \& Peterson, S. J. (2008). Authentic Leadership: Development and Validation of a Theory-Based Measuret. Journal of Management, 34(1), 89-126. doi:doi:10.1177/0149206307308913

Withey, M. J., \& Cooper, W. H. (1989). Predicting exit, voice, loyalty, and neglect. Administrative Science Quarterly, 34, 521-539. doi:10.2307/2393565

Wright, B. E. (2001). Public Sector Work Motivation: A Review of the Current Literature Model and a Revised Conceptual Model. Journal of Public Administration Research \& Theory, 11(4), 559.

Wright, B. E., Donald, P. M., \& Sanjay, K. P. (2012). Pulling the Levers: Transformational Leadership, Public Service Motivation, and Mission Valence. Public Administration Review, 72(2), 206-215.

Wu, M. (2006). Hofstede's cultural dimensions 30 years later: A study of Taiwan and the United States. Intercultural Communication Studies, 15(1), 33.

Xu, H., van de Vliert, E., \& van der Vegt, G. (2005). Breaking the silence culture: Stimulation of participation and employee opinion withholding cross-nationally. Management and Organization Review, 1(3), 459-482.

Yuan, F., \& Zhou, J. (2015). Effects of cultural power distance on group creativity and individual group member creativity. Journal of Organizational Behavior, 36(7), 990-1007. doi:10.1002/job.2022 